Article

\title{
Interval Optimization-Based Unit Commitment for Deep Peak Regulation of Thermal Units
}

\author{
Yinping Yang, Chao Qin *, Yuan Zeng and Chengshan Wang \\ Key Laboratory of Smart Grid of Ministry of Education, Tianjin University, Tianjin 300072, China; \\ yangyp88@tju.edu.cn (Y.Y.); zengyuan@tju.edu.cn (Y.Z.); cswang@tju.edu.cn (C.W.) \\ * Correspondence: qinchao@tju.edu.cn; Tel.: +86-139-2081-9732
}

Received: 30 January 2019; Accepted: 6 March 2019; Published: 10 March 2019

\begin{abstract}
The deep peak regulation of thermal units is an important measure for coping with significant wind power penetration. In this paper, based on interval optimization, a novel multi-objective unit commitment method is proposed considering the deep peak regulation of thermal units. In the proposed method, a thermal power cost model was developed to accurately determine the economic performance of three different peak regulation scenarios, particularly of the deep peak regulation scenario. The midpoint and width of the cost interval are simultaneously considered in the optimization process. The non-dominated sorting GA-II (NSGA-II) algorithm was incorporated into the model for a coordinated control of the midpoint and width of the obtained cost interval for further optimization. Considering that significant wind penetration results in greater nodal variations, the affine arithmetic was employed to solve nodal uncertainties, so that all system variations can be addressed. The method proposed in this paper was validated by a modified IEEE-39 bus system. The results showed that it serves as a useful tool for power dispatchers to obtain robust and economic solutions at different wind power prediction accuracies.
\end{abstract}

Keywords: deep peak regulation; unit commitment; interval number; optimization methods

\section{Introduction}

The global installed capacity of wind power is projected to exceed $2000 \mathrm{GW}$ by 2030 . Owing to the intermittence, stochasticity, and anti-peak regulation of wind power, a significant wind penetration results in greater variations in the net load demand for thermal power. This results in greater challenges for the operation of power systems, particularly those with limited power regulation resources. This has been a major cause of significant wind power curtailment in China [1]. With the increasing wind power curtailment, there are increasingly stronger calls for more significant thermal power regulation methods for power systems with large-scale wind power.

However, it is impossible to handle the large variability brought by significant wind penetration when employing regular thermal power output regulation. This will result in significant wind power curtailment. A full utilization of wind power requires a certain number of thermal generation units to operate below their minimum technical outputs. In other words, these thermal units will be operated in the deep peak regulation stage. A significant output regulation not only results in greatly reduced operating efficiency for thermal units but also but also leads to the shortened service life of thermal units, thus incurring implicit costs.

There is limited research in the field of operation concerning economic dispatch in consideration of deep peak regulation. Lin et al. [2] and Anderson et al. [3] analyzed technical factors affecting the capability of thermal units for deep peak regulation and proposed energy cost models for different modes of thermal power output regulation. The economic and operational characteristics of thermal units in deep peak regulation is different from those in regular peak regulation [4]. Xie et al. [5] 
and Cheng et al. [6] explained the operation characteristics of steam turbines under the condition of deep peak regulation. The different characteristics require different UC (unit commitment) modeling techniques. To the best of the authors' knowledge, no research has been conducted in this regard.

Considering that thermal units in deep peak regulation are necessitated by significant wind penetration, the uncertainty with wind power must be investigated as a major input variable. Although many techniques have been developed for wind power prediction, the mean absolute percent error (MAPE) obtained using most established software packages is still in the range of 14-20\% [7-9]. Under the condition of significant wind penetration, the variability of node injection remains significant.

The mainstream techniques for coping with the uncertainty in nodal volatility include stochastic, chance-constrained, and robust unit commitment. Chance-constrained and stochastic unit commitment solutions [10-12] can ensure system security only at certain levels of probability; this shows the possibility of system hazards in some special scenarios. This violates the principle that security is the first priority of system operation. The robust unit commitment [13] solution takes into account different nodal volatilities; however, its objective function is only to minimize the total cost in the worst scenario, so it is not comprehensive from an economic perspective. The interval arithmetic is similar to the robust technique to a certain extent, in that both are capable of providing a solution for system fluctuations; however, the interval arithmetic exhibits the advantage of providing an optimal interval considering economic constraints. Furthermore, the interval arithmetic is capable of controlling parameters of the optimal interval, such as the width and height, and therefore can provide more comprehensive and economic solutions.

Owing to its unique advantages, interval arithmetic has been widely applied to power systems. For example, it is used to account for uncertainties with load when solving the power flow problem [14], addressing multiple indeterminate parameters of electric energy markets [15], and providing good solutions for reactive power optimization [16] and optimal scheduling [17].

Wang et al. [18] proposed a novel interval arithmetic-based unit commitment model for improving system security and economy. The model considers the optimal cost of different wind power prediction scenarios as the objective function. It can provide dispatch strategies that are flexible and reliable both temporally and spatially. However, the thermal units remain in deep peak regulation, resulting in a significant increase in fuel consumption and generation unit loss. This leads to a significant increase in the kilowatt generation cost. In summary, the prediction optimization-based interval arithmetic is prone to huge errors and is unlikely to obtain the optimal interval. Zhang et al. [16] suggested that the optimality of an interval result can be assessed by its midpoint and width. The objective of this study is to achieve the coordinate optimization of the midpoint and width of the cost interval. In summary, on the basis of the overall interval optimization, the addition of the objective function of the interval width contributed to the higher robustness of the obtained interval.

The contributions of the study can be summarized as follows:

(1) In this study, a unit commitment model was proposed to consider the deep peak regulation of thermal units. Compared with traditional unit commitment models, the proposed model includes an economic model that integrates the explicit and implicit costs of generation units and conforms to the practical condition of deep peak regulation;

(2) The NSGA-II was employed to realize the overall optimization of the cost interval. The midpoint and width of this interval are considered in the optimization, instead of the optimization of prediction, thus reducing the computation error due to the kilowatt generation cost and improving the accuracy and robustness of the computed interval;

(3) An affine arithmetic was employed to replace the traditional interval arithmetic for power flow analysis [19-23]; the affine arithmetic takes into account the correlation between multiple buses and is able to obtain a remarkably smaller interval than the traditional arithmetic. Furthermore, the unit ramping constraints are taken into account for a better simulation of the actual power grids. 


\section{Model Formulation}

The objective of the unit commitment problem is to provide a $24 \mathrm{~h}$ generation dispatch schedule. Compared to the traditional unit commitment optimization, deep unit commitment optimization takes into account more parameters of explicit and implicit costs. This will be covered in Section 2.1. Section 2.2 presents the interval arithmetic-based unit commitment model, including a detailed procedure for optimizing the objective function.

\subsection{Cost Model for the Deep Power Regulation (DPR) of Thermal Units}

Based on the operation stages and energy consumption characteristics of thermal units, the peak regulation process can be divided into the following three stages: regular peak regulation (RPR), deep peak regulation (DPR), and deep peak regulation with oil (DPRO), as shown in Figure 1.

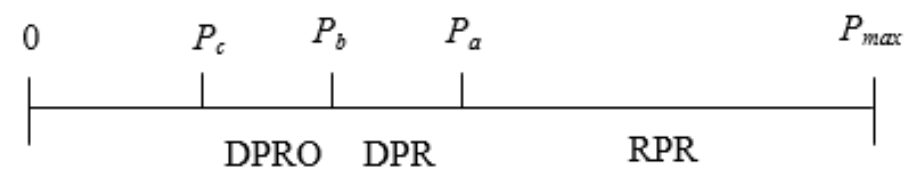

Figure 1. Schematic diagram of the unit peak regulation process. $P_{a}$ is the minimum technical capacity of the unit at the regular peak regulation (RPR) stage, $P_{b}$ is the minimum rated capacity at the deep peak regulation (DPR) stage, and $P_{c}$ is the minimum stable output at the deep peak regulation with oil (DPRO) stage.

The cost of a thermal unit at the various stages of the peak regulation process includes the cost of coal consumed and is usually computed according to the characteristics of coal consumption. The cost of the coal consumed for power generation can be expressed as

$$
f(P)=\left(a P^{2}+b P+c\right) S_{c o a l}
$$

At the DPR and DPRO stages, significantly suppressing the power of a thermal unit results in high thermal stresses in its rotor shaft; the alternating high thermal stresses result in low-cycle fatigue wear and creep wear, which in turn lead to significant deformation and even the fracture of the unit and thus the reduced service life of the unit. The computation of the service life of a steam turbine's rotor is a very complicated problem; there is no generally accepted formula for solving the problem. In this study, the low-cycle fatigue life of the rotor was computed according to the low-cycle fatigue characteristic relation $(\Delta \varepsilon-N)$ of the rotor material [2].

The Manson-Coffin equation for representing the relationship between the total strain and the number of cycles to failure of the rotor is expressed as the following functional relationship:

$$
\Delta \varepsilon_{t}=\frac{\sigma_{f}}{E}\left(2 N_{t}\right)^{d}+\varepsilon_{f}\left(2 N_{t}\right)^{e}
$$

According to the stress and centrifugal tangential stress of the generator rotor and number of cycles to failure $N_{t}(P)$ of the rotor obtained via the Manson-Coffin equation, the cost of unit loss can be expressed as:

$$
w_{\cos t}(P)=\frac{1}{2 N_{t}(P)} S_{\text {unit }} .
$$

At the DPRO stage, the boiler dramatically deteriorates in terms of burning stability, hydrodynamics, and security performance. As a result of the unstable boiler burning, oil needs to be injected into the unit to maintain its safe operation. The cost of oil injection can be expressed as

$$
w_{\text {oil }}=E_{\mathrm{cos} t} S_{\text {oil }}
$$


In summary, the operating cost of a thermal unit is different under different operating conditions. In this study, the peak regulation cost for a thermal unit can be expressed as the following piece-wise function (the costs of fuel and fuel injections are defined as explicit costs, and the cost of generator unit loss is defined as implicit cost):

$$
C(P)=\left\{\begin{array}{cc}
f(P) & P_{a}<P \leq P_{\max } \\
f(P)+w_{\cos t}(P) & P_{b}<P \leq P_{a} \\
f(P)+w_{\cos t}(P)+C_{o i l} & P_{c}<P \leq P_{b}
\end{array}\right.
$$

\subsection{Interval Arithmetic-Based Unit Commitment Model}

The interval arithmetic represents an uncertain variable as an interval and computes the reliable range of the variable in the model. The main objective of the unit commitment problem is to provide an optimal startup/shutdown schedule for a set of units under various operating conditions. The interval arithmetic-based unit commitment model can produce reliable power dispatch schedules suitable for multiple operating conditions; it provides robust and economic solutions.

The objective of this study was to find the most economic unit commitment solution while ensuring security and reliability; the objective function was defined as the optimal economic performance. The deterministic unit commitment model is expressed as

$$
\begin{gathered}
\left.\min F=\min \sum_{t \in T} \sum_{i \in n G} I^{G}(t) \cdot C\left(P_{i}^{G}(t)\right)+\sum_{t \in T} \sum_{i \in n G} I^{G}(t)\left[1-I^{G}(t-1)\right] S_{O N}^{G}+I^{G}(t-1)\left[1-I^{G}(t)\right] S_{O F F}^{G}\right\}, \\
\sum_{i \in n G} P_{i}^{G}(t)=\sum_{i \in n D} P_{i}^{D}(t), \forall i, \forall t \\
I^{G}(t) P_{i, \min }^{G} \leq P_{i}^{G}(t) \leq I^{G}(t) P_{i, \max }^{G}, \forall G \in n G, \forall t, \\
P_{i}^{G}(t+1)-P_{i}^{G}(t) \leq P_{i, \max }^{G}+\left(R U^{G}-P_{i, \max }^{G}\right) I^{G}(t), \forall G \in n G, \forall t \\
P_{i}^{G}(t)-P_{i}^{G}(t+1) \leq P_{i, \min }^{G}+\left(R D^{G}-P_{i, \min }^{G}\right) I^{G}(t), \forall G \in n G, \forall t \\
-P_{\max }^{L} \leq P^{L}(t) \leq P_{\max }^{L}, \forall L, \forall t, \\
\left(T_{O N}^{G}(t)-T_{U P}^{G}\right)\left(I^{G}(t-1)-I^{G}(t)\right) \geq 0, \forall G \in n G, \forall t \\
T_{O N}^{G}(t)=T_{O N}^{G}(t-1) I^{G}(t), \forall G \in n G, \forall t \\
\left(T_{O F F}^{G}(t)-T_{D O N N}^{G}\right)\left(I^{G}(t)-I^{G}(t-1)\right) \geq 0, \forall G \in n G, \forall t \\
T_{O F F}^{G}(t)=T_{O F F}^{G}(t-1)\left(1-I^{G}(t)\right) . \forall G \in n G, \forall t .
\end{gathered}
$$

The objective function (6) is defined as the minimum total operating cost, including the operating cost and startup/shutdown cost of a set of generation units. Equation (7) represents the power balance of the system; that is, the total unit output is equal to the total net load. Equation (8) represents the constraints of the unit power output. Equations (9) and (10) represent the ramping constraints of the generation unit. Equation (11) represents the constraints of transmission capacity. Equations (12) to (15) represent the constraints on the continuous on and off times of the thermal units.

The uncertain power injection at wind power and load buses can be expressed as an interval $\left[\underline{P}_{i}^{D}, \bar{P}_{i}^{D}\right]$; this interval covers a confidence interval at a certain probability and can be obtained using various traditional prediction methods.

If the power injection at a load bus is represented as an interval, then the power injection at a unit bus and the line power can be represented as intervals. Thus, Equations (7) to (11) can be revised as Equations (16) to (20), respectively:

$$
\sum_{i \in n G}\left[\underline{P}_{i}^{G}(t), \bar{P}_{i}^{G}(t)\right]=\sum_{i \in n D}\left[\underline{P}_{i}^{D}(t), \bar{P}_{i}^{D}(t)\right], \forall i, \forall t,
$$




$$
\begin{gathered}
I^{G}(t) P_{i, \min }^{G} \leq\left[\underline{P}_{i}^{G}(t), \bar{P}_{i}^{G}(t)\right] \leq I^{G}(t) P_{i, \text { max }}^{G}, \forall G \in n G, \forall t \\
{\left[\underline{P}_{i}^{G}(t+1), \bar{P}_{i}^{G}(t+1)\right]-\left[\underline{P}_{i}^{G}(t), \bar{P}_{i}^{G}(t)\right] \leq P_{i, \max }^{G}+\left(R U^{G}-P_{i, \max }^{G}\right) I^{G}(t), \forall G \in n G, \forall t} \\
{\left[\underline{P}_{i}^{G}(t), \bar{P}_{i}^{G}(t)\right]-\left[\underline{P}_{i}^{G}(t+1), \bar{P}_{i}^{G}(t+1)\right] \leq P_{i, \min }^{G}+\left(R D^{G}-P_{i, \min }^{G}\right) I^{G}(t), \forall G \in n G, \forall t} \\
-P_{\max }^{L} \leq\left[\underline{P}^{L}(t), \bar{P}^{L}(t)\right] \leq P_{\max }^{L}, \forall L, \forall t
\end{gathered}
$$

If the unit output is represented as an interval, then the solution of the objective function $F$ is also an interval. An appropriate criterion is then required to assess the optimality of the interval.

Unlike previous studies, the optimality of the interval solution of the objective function is assessed by its midpoint and magnitude, which are represented as $F_{M}$ and $F_{R}$, respectively.

Thus, the unit commitment model can be rewritten as

$$
\begin{aligned}
& \min \left\{F_{M}, F_{R}\right\}=\min \{\operatorname{mid}(F(I, X), \operatorname{rad}(F(I, X)))\} \\
& \text { s.t. }\left\{\begin{array}{c}
h(I, X)=[\underline{h}, \bar{h}] \\
g^{\min } \leq g(I, X) \leq g^{\max } \\
k(I) \geq 0
\end{array},\right.
\end{aligned}
$$

where $X$ is the state variable of the system, including the interval variables for power flow computation, such as $P_{i}^{G}, P_{i}^{D}$, and $P^{L}$. I represents the controllable variables for the computation; it is a real number, including unit commitment decision variable $I^{G}$ and the two auxiliary variables $T_{O N}^{G}$ and $T_{O F F}^{G} \cdot[\underline{h}, \bar{h}]$ is the interval formed from the combination of the variables in Equations (16)-(20). The first constraint is the equation representing the interval equation used for the computation; i.e., Equation (16). The second constraint is the interval inequalities used for the computation; i.e., Equations (17) to (20). The third constraint represents the inequalities for integer variables, mainly about the unit commitment decision variable; i.e., Equations (12) to (15).

\section{Solution Methods}

As shown in Equation (21), the proposed model is a multi-objective nonlinear mixed integer programming problem. It can be solved using commercial solvers, such as CPLEX Optimizer 12.6, which have been widely used in solving traditional unit commitment models.

In this paper, a solution method based on the NSGA-II and affine arithmetic is proposed to solve the model given in Section 2. Figure 2 shows the details of the solution method.

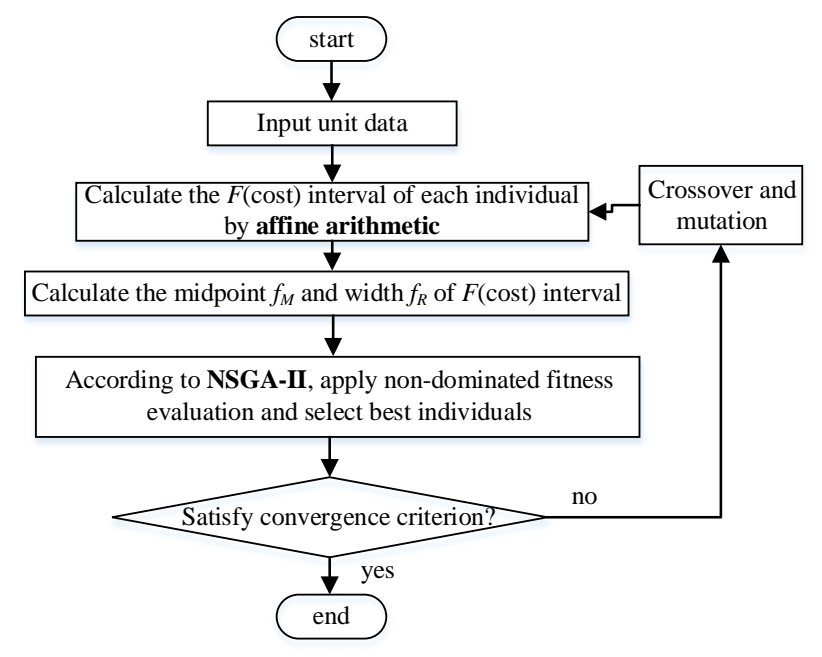

Figure 2. Flowchart for solving the unit commitment model. 
The NSGA-II is a common multi-objective optimization method and is particularly suitable for solving non-convex and mixed integer problems. We first initialized the population to obtain several initial solutions. The optimum interval of each solution was then obtained using the affine arithmetic. Each solution was then assessed using fuzzy decision-making. Crossover and mutation were then performed, thereby choosing the final unit commitment decision. Section 3.1 presents the genetic algorithm-based procedure for solving the unit commitment problem, including the process for population initialization and crossover and mutation. Section 3.2 presents the fuzzy process and the procedure to obtain the non-dominated solution for the multi-objective decision-making method. Section 3.3 describes the procedure for determining the optimal interval of the solution by using the affine arithmetic method.

\subsection{Genetic Algorithm-Based Unit Commitment Solution}

In this study, the unit commitment model was solved using an integer code-based genetic algorithm, which exhibits rapid computation and convergence [24].

\subsubsection{Chromosome Definition}

In the integer-coded genetic algorithm, the ON/OFF operating statuses of the generation units in the entire power dispatch cycle are represented as integers. Each chromosome was constituted by a continuous series of integers $\left\{T_{C}^{G}, C=1,2, \ldots, \bar{C}_{G}\right\}$, representing the operating schedule of a unit during the unit commitment horizon, with positive integers representing the duration of continuous unit operation and negative integers representing the unit reservation. The sum of the absolute values of the alternating sign integers must equal the scheduling horizon:

$$
\sum_{C=1}^{\bar{C}_{G}}\left|T_{C}^{G}\right|=T
$$

The duration of the first cycle of operation of unit $G, T_{1}^{G}$ is initialized so that the unit continues the operating mode of the last cycle of the previous scheduling day for at least as many hours as required to satisfy the minimum up/down time constraints.

$$
T_{1}^{G}=\left\{\begin{array}{c}
+R A N D\left(\max \left(0, T_{U P}^{G}-T_{0}^{G}\right), T\right), \text { if } T_{0}^{G}>0 \\
-R A N D\left(\max \left(0, T_{D O W N}^{G}+T_{0}^{G}\right), T\right), \text { if } T_{0}^{G}>0
\end{array}\right.
$$

The duration of the $C$ th cycle of operation of unit $G, T_{C}^{G}$ is calculated while taking into account the unit's minimum up and down time constraints, the unit commitment horizon, and the duration of the $\left(\bar{C}_{G}-1\right)$ prior cycle of operation of the unit.

If $T_{C_{-} 1}^{G}<0$, cycle $C$ represents the $\mathrm{ON}$ status with the duration

$$
T_{C}^{G}=\left\{\begin{array}{cc}
+R A N D\left(T_{U P}^{G}, R T_{C-1}^{G}\right) & \text { if }\left(R T_{C-1}^{G}>T_{U P}^{G}\right) \\
+R T_{C-1}^{G} & \text { otherwise. }
\end{array}\right.
$$

If $T_{C-1}^{G}>0$, cycle $C$ represents the OFF status with the duration

$$
T_{C}^{G}=\left\{\begin{array}{lr}
-R A N D\left(T_{D O W N}^{G}, R T_{C-1}^{G}\right) & \text { if }\left(R T_{C-1}^{G}>T_{D O W N}^{G}\right) \\
-R T_{C-1}^{G} & \text { otherwise }
\end{array},\right.
$$

where $R T_{C^{-}}^{G}$ represents the scheduling time remaining after the allocation of the first $C-1$ cycles:

$$
R T_{C}^{G}=T-\sum_{C=1}^{C-1}\left|T_{C}^{G}\right|
$$


The duration of the last cycle for unit $G$ is determined by the duration of the previous $\bar{C}_{G}-$ 1 cycles:

$$
T_{\bar{C}_{G}}^{G}=R T_{\bar{C}_{G}}^{G}
$$

\subsubsection{Chromosome Evolution}

The genetic algorithm is based on the biological evolution mechanism of natural selection and maintaining the most adaptive offspring. The individuals for crossover and mutation are randomly selected using roulette selection. The typical genetic algorithm is not suitable for integer coding, so a special evolution method was employed in this study.

- Crossover

The crossover for this method was performed for the best chromosome of population generations with a $30 \%$ probability. It randomly selects two units in the chromosome and performs the following actions:

i. Copying the schedule of the first unit to the second;

ii. Copying the schedule of the second unit to the first;

iii. Swapping the schedules of the two units.

Each of the above actions take place only if the units' minimum up/down times are the same. Thus, violations of these constraints are avoided.

- Mutation

The typical chromosome structure can be expressed as

$$
C_{v}=\left\{T_{1}^{1}, T_{2}^{1}, \ldots, T_{\bar{C}_{1}}^{1}, \ldots, T_{1}^{G}, \ldots, T_{\bar{C}_{G}}^{G}\right\} .
$$

When unit $G$ mutates in cycle $C$, the duration of the new cycle $C$ can be expressed as

$$
T_{C, M U T}^{G}= \begin{cases}T_{C}^{G}+\Delta\left(g, T_{C, \max }^{G}-T_{C}^{G}\right) & \text { if } r=0 \\ T_{C}^{G}-\Delta\left(g, T_{C}^{G}-T_{C, \min }^{G}\right) & \text { if } r=1,\end{cases}
$$

where $r$ is a random number of $0 / 1$. When the number of cycles $C>1, T_{C, \max }^{G}=R T_{C-1}^{G}$ and $T_{C, \min }^{G}$ $=T_{U P}^{G}$ or $T_{D O W N}^{G}$, when $C=1, T_{C, \min }^{G}$ and $T_{C, \max }^{G}$ are determined by using Equation (23). Function $\Delta(g, y)$ returns a value in the range $[0, y]$ such that the probability of the value returned being close to 0 increases with $g$.

$$
\Delta(g, y)=y\left(1-\xi^{\left(1-\frac{g}{G}\right)^{b}}\right) .
$$

where $\xi$ is a floating-point number in the interval $[0,1], g$ is the number of operating units, $G$ is the maximum number of units, and $b$ is a control parameter and is assigned an empirical value of 0.2 .

Further, as the durations of the operating cycles depend on each other, the mutation processes do not end until after the entire unit commitment horizon has been covered.

\subsection{NSGA-II Decision-Making Method}

The NSGA-II algorithm has the same mechanism in population generation and evaluation in comparison to single-objective genetic algorithms. As multi-objective optimization requires the coordinated formation of non-dominated solutions, NSGA-II can additionally provide a decision-making method for a non-dominated solution, and difference criteria are made in solution selection.

The NSGA-II algorithm uses fuzzy decision-making methods and models decision makers' preferences in mathematical equations. This algorithm assigns a membership to each objective, and the membership shows a degree that meets the decision maker's criteria about that objective. The 
membership function value ranges from zero to one, with zero indicating incompatibility and one indicating full compatibility with the decision maker's preferences.

$$
\mu_{f_{i}}(X)= \begin{cases}0 & f_{i}(X)>f_{i}^{\max } \\ \frac{f_{i}^{\max }-f_{i}(X)}{f_{i}^{\max }-f_{i}^{\min },} & f_{i}^{\min } \leq f_{i}(X) \leq f_{i}^{\max } \\ 1 & f_{i}(X)<f_{i}^{\min }\end{cases}
$$

With the membership function defined, the decision maker assigns his/her desirable level for each objective function. The final solution is then acquired by solving the optimization problems by minimizing the total deviations in the memberships:

$$
\min _{X \in \text { solution }_{i=1}} \sum^{m}\left|\mu_{i}-\mu_{f_{i}}(X)\right|^{n} n \in[1, \infty),
$$

where $n$ is the sensitivity parameter of the correlation between the several solutions.

In this study, two membership functions are defined as the midpoint and width, respectively, of the acquired cost interval. As the two objectives are conflicting, the two objectives are compromised by assigning different membership values such that the required solution can be obtained.

\subsection{Cost Interval Calculation Based on Affine Arithmetic}

The interval algorithm has been used to solve unit commitment with uncertain power injections. It uses a deterministic range for a direct solution; the solution is relatively conservative and the width of the resulting interval is significantly greater than the actual width.

However, for power systems with large-scale wind power and deep peak regulation, bus power injections may vary in a very wide range. In this situation, the interval algorithm may cause large errors.

To overcome the disadvantages of the interval algorithm, the affine arithmetic is employed to solve the model proposed in this paper. The affine arithmetic was integrated into the model to replace the traditional interval arithmetic, thereby significantly reducing the bias inherent in the interval arithmetic. Moreover, the affine arithmetic was improved by incorporating unit ramping constraints.

\subsubsection{Affine Arithmetic}

Affine arithmetic is an improved interval algorithm. It uses affine to record the correlation between buses and then uses this correlation information to limit the extension of error; thus, it can provide narrower intervals.

An affine representation $\widetilde{x}$ of a value $x$ is represented in the following form:

$$
\widetilde{x}=x_{0}+x_{1} \varepsilon_{1}+x_{2} \varepsilon_{2}+\ldots+x_{n} \varepsilon_{n}
$$

A major characteristic of affine arithmetic is the use of the same noise variable to represent multiple variables; this noise variable reveals the correlation between the partials caused by several variables. Thus, affine arithmetic can effectively narrow the boundaries:

$$
\begin{gathered}
\widetilde{x} \pm \widetilde{y}=\left(x_{0} \pm y_{0}\right)+\left(x_{1} \pm y_{1}\right) \varepsilon_{1}+\left(x_{2} \pm y_{2}\right) \varepsilon_{2}+\ldots+\left(x_{n} \pm y_{n}\right) \varepsilon_{n} \\
\alpha \widetilde{x}=\left(\alpha x_{0}\right)+\left(\alpha x_{1}\right) \varepsilon_{1}+\left(\alpha x_{2}\right) \varepsilon_{2}+\ldots+\left(\alpha x_{n}\right) \varepsilon_{n} \forall \alpha \in R \\
\widetilde{x} \pm \lambda=\left(x_{0} \pm \lambda\right)+x_{1} \varepsilon_{1}+x_{2} \varepsilon_{2}+\ldots+x_{n} \varepsilon_{n} \forall \lambda \in R
\end{gathered}
$$

Calculations are done with each correlated component, and the results are obtained by expanding and rearranging same noise $\varepsilon_{i}$. 
This can be mathematically expressed as:

$$
\widetilde{z}=f(\widetilde{x}, \widetilde{y})=f\left(x_{0}+x_{1} \varepsilon_{1}+x_{2} \varepsilon_{2}+\ldots+x_{n} \varepsilon_{n}, y_{0}+y_{1} \varepsilon_{1}+y_{2} \varepsilon_{2}+\ldots+y_{n} \varepsilon_{n}\right)=f\left(\varepsilon_{1}, \varepsilon_{2}, \ldots, \varepsilon_{n}\right)
$$

\subsubsection{Computation of Cost Interval}

According to the methods proposed in Sections 3.1 and 3.2, the unit commitment problem can be solved using the NSGA-II algorithm. This section describes how to obtain the optimal cost interval based on an established unit commitment schedule.

1. The computation model based on affine arithmetic

The computation method employed in this study is developed from the affine arithmetic-based optimal power flow computation method proposed by Pirnia et al. [21] by incorporating unit ramping constraints such that the ramping capacity required for wind power-integrated systems can be addressed. The model for computing the cost interval for a given unit commitment schedule can be expressed as

$$
\min F\left(\widetilde{P}^{G}\right)=\sum_{t=1}^{24} F\left(\widetilde{P}_{i}^{G}(t)\right)
$$

s.t.

$$
\begin{gathered}
\sum_{i \in n G} \widetilde{P}_{i}^{G}(t)=\sum_{i \in n D} \widetilde{P}_{i}^{D}(t) \forall i \in N, \forall t, \\
\Delta \widetilde{P}_{i}\left(\widetilde{\theta}_{i}(t), \widetilde{P}_{i}^{G}(t), \widetilde{P}_{i}^{D}(t)\right)=0, \forall i \in N, \forall t \\
I^{G}(t) P_{i, \min }^{G} \leq \widetilde{P}_{i}^{G}(t) \leq I^{G}(t) P_{i, \max }^{G}, \forall i \in n G, \forall t \\
\Delta_{\text {DOWN }}^{G}(t) \leq \widetilde{P}_{i}^{G}(t+1)-\widetilde{P}_{i}^{G}(t) \leq \Delta_{U P}^{G}(t), \forall i \in n G, \forall t \\
-P_{\max }^{L} \leq \widetilde{P}^{L}(t) \leq P_{\max }^{L}, \forall L, \forall t
\end{gathered}
$$

Equation (38) represents the power balance equation of load and generation in the form of the sum of the affine intervals. Equation (39) is the bus injection equation, indicating that the interval of bus injection resulting from the phase angle affine should be consistent with the given generation and load intervals. Equations (40) to (42) show that the intervals of generation power and line power should be subjected to constraints and that the ramping of units should be subjected to the system fluctuation requirement.

2. Bilinearization of the objective function

As shown in Equation (43), the optimal interval is expressed as the minimum upper and lower limits of the desired optimal interval. Thus, the resulting interval with the minimum upper and lower limits is the optimal interval.

$$
\min F(\widetilde{x}) \Leftrightarrow\left\{\begin{aligned}
\min F_{\text {low }}(\widetilde{x}) & =\min F_{\text {low }}\left(\left[x_{\text {low }}, x_{\text {up }}\right]\right) \\
\min F_{\text {up }}(\widetilde{x}) & =\min F_{\text {up }}\left(\left[x_{\text {low }}, x_{\text {up }}\right]\right)
\end{aligned}\right.
$$

The objective interval is the optimal cost interval, with the upper and lower limits of the interval representing the maximum and minimum costs of the generation interval, respectively, which can meet the net load interval.

The inclusion of ramping constraints means that the costs obtained based on the scenarios of minimum and maximum net loads are subjected to additional constraints; more specifically, decreasing the boundary at one side of the interval may lead to an increase in the boundary at the other side. Therefore, it is difficult to directly obtain the optimal interval. 
In this paper, the sum of the weights assigned for the upper and lower limits is defined as the objective function for representing the optimal interval:

$$
\begin{aligned}
& o b j_{1}=\min F_{l o w}(\widetilde{x}) \quad o b j_{2}=\min F_{u p}(\widetilde{x}) \\
& o b j=\lambda_{1} \cdot o b j_{1}+\lambda_{2} \cdot o b j_{2},
\end{aligned}
$$

$\lambda_{1}$ and $\lambda_{2}$ are the weight coefficients for the upper and lower limits, respectively, of the cost interval in the final objective function. Both are assigned a value of 0.5 .

3. The computational procedure of affine arithmetic

The affine variable in the model includes a center variable and the corresponding magnitude of noise. The central value of the variable can be determined using deterministic optimal power flow (OPF) analysis, and the deterministic load required for the OPF analysis can be obtained using the midpoint of the load as follows:

$$
P_{i, 0}^{D}(t)=\frac{P_{i, \text { min }}^{D}(t)+P_{i, \max }^{D}(t)}{2} \forall i \in n D
$$

To obtain the noise magnitudes of the corresponding component, a sensitivity analysis is carried out, because the uncertain inputs at the generation and load buses can cause certain magnitudes of disturbance. The maximum power fluctuations at the different buses can be expressed as

$$
\begin{gathered}
\Delta P_{i}^{D}(t)=\frac{P_{i, \max }^{D}(t)-P_{i, \text { min }}^{D}(t)}{2} \forall i \in n D, \\
\Delta P_{i}^{G}(t)=\max \left\{P_{i, \text { max }}^{G}-P_{i, 0}^{G}(t), P_{i, 0}^{G}(t)-P_{i, \text { min }}^{G}\right\} \forall i \in n G, \forall t .
\end{gathered}
$$

Therefore, the noise magnitudes of the phase angle can be obtained as follows:

$$
\begin{gathered}
\theta_{i j}(t)=\left.\frac{\partial \theta_{i}(t)}{\partial P_{j}^{D}(t)}\right|_{0} \approx \frac{\theta_{i, N}(t)-\theta_{i, 0}(t)}{\Delta P_{j}^{D}(t)} \forall i \in N, \forall j \in n D, \forall t, \\
\theta_{i j}(t)=\left.\frac{\partial \theta_{i}(t)}{\partial P_{j}^{G}(t)}\right|_{0}=\frac{\theta_{i, N}(t)-\theta_{i, 0}(t)}{\Delta P_{j}^{G}(t)} \forall i \in N, j \in n G, \forall t .
\end{gathered}
$$

The affine form of the phase angle at a bus can be then determined based on the midpoint and noise values. The phase angle affine is a linear expression consisting of the noise variable $\varepsilon_{j}$; the noise represents the uncertainty in the active power injection at bus $j$. The maximum ranges of injection at the different buses are expressed in Equations (51) to (54).

$$
\begin{gathered}
\widetilde{\theta}_{i}(t)=\theta_{i, 0}(t)+\sum_{j=1}^{N} \theta_{i j}(t) \varepsilon_{j}(t) \forall i \in N, \\
-1 \leq \varepsilon_{j}(t) \leq 1, \forall j \in n D, \forall t \\
\varepsilon_{j, \min }(t) \leq \varepsilon_{j}(t) \leq \varepsilon_{j, \max }(t) \forall j \in n G, \forall t, \\
\varepsilon_{j, \max }(t)=\frac{\max \left\{P_{i, \max }^{G}-P_{i, 0}^{G}(t), P_{i, 0}^{G}(t)-P_{i, \min }^{G}\right\}}{P_{i, \max }^{G}-P_{i, 0}^{G}(t)} \forall j \in n G, \forall t, \\
\varepsilon_{j, \max }(t)=\frac{\max \left\{P_{i, \max }^{G}-P_{i, 0}^{G}(t), P_{i, 0}^{G}(t)-P_{i, \min }^{G}\right\}}{P_{i, \max }^{G}-P_{i, 0}^{G}(t)} \forall j \in n G, \forall t .
\end{gathered}
$$


The variation in the phase angle will directly cause a variation in the lines. Thus, the affine form of the lines can be expressed as

$$
\begin{aligned}
\widetilde{P}^{L}(t) & =B_{i j}\left[\left(\widetilde{\theta}_{i}(t)-\widetilde{\theta}_{j}(t)\right)\right] \\
& =B_{i j}\left[\left(\theta_{i, 0}(t)-\theta_{j, 0}(t)\right)+\sum_{k=1}^{N}\left(\theta_{i k}(t)-\theta_{j k}(t)\right) \varepsilon_{k}(t)\right] \forall i, j \in L, \forall t .
\end{aligned}
$$

Similarly, the imbalance in the bus power injection directly caused by a phase angle variation can be expressed as

$$
\Delta \widetilde{P}_{i}\left(\widetilde{\theta}_{i}, \widetilde{P}_{i}^{G}, \widetilde{P}_{i}^{D}\right)=\widetilde{P}_{i}(t)-\sum_{j=1}^{N} B_{i j}\left(\widetilde{\theta}_{i}(t)-\widetilde{\theta}_{j}(t)\right)=0 \forall i \in N, \forall t .
$$

The affine form of the active power at a bus can be directly obtained using the given affine form of the phase angle, and the affined power injection and phase angle have the same control variable $\varepsilon_{j}$. Thus, the power injection at a bus is determined by the power injection at all the other buses:

$$
\widetilde{P}_{i}(t)=P_{i, 0}(t)+\sum_{j=1}^{N} P_{i j}(t) \varepsilon_{j}(t), \forall i \in N, \forall t
$$

As described above, two deterministic problems need to be solved to obtain the upper and lower limits of the optimal interval. Specifically, to determine the upper and lower limits of the interval, $\left\{\varepsilon_{1, \text { up }}(t), \varepsilon_{2, \text { up }}(t), \ldots, \varepsilon_{n, u p}(t)\right\}$ and $\left\{\varepsilon_{1, \text { low }}(t), \varepsilon_{2, \text { low }}(t), \ldots ., \varepsilon_{n, \text { low }}(t),\right\}$ needs to be solved.

4. The final optimization model

The final optimization model can be expressed as

$$
\begin{gathered}
o b j=\lambda_{1} \cdot o b j_{1}+\lambda_{2} \cdot o b j_{2}, \\
o b j_{1}=\min F_{l o w}\left(\widetilde{P}_{i}^{G}\right)=\min \sum_{t=1}^{24} \sum_{i=1}^{n G} F\left[P_{i, l o w}^{G}(t), P_{i, u p}^{G}(t)\right], \\
o b j_{2}=\min F_{u p}\left(\widetilde{P}_{i}^{G}\right)=\max \sum_{t=1}^{24} \sum_{i=1}^{n G} F\left[P_{i, l o w}^{G}(t), P_{i, u p}^{G}(t)\right],
\end{gathered}
$$

s.t.

$$
\begin{gathered}
\sum_{i \in n G} \widetilde{P}_{i, \text { up }}^{G}(t)=\sum_{i \in n D} P_{i, \max }^{D}(t) \forall i \in N, \forall t, \\
\sum_{i \in n G} \widetilde{P}_{i, \text { low }}^{G}(t)=\sum_{i \in n D} P_{i, \min }^{D}(t) \forall i \in N, \forall t, \\
\widetilde{P}_{i, \text { up }}^{D}(t)=P_{i, \max }^{D}(t), \forall i \in n D, \forall t, \\
\widetilde{P}_{i, \text { low }}^{D}(t)=P_{i, \min }^{D}(t), \forall i \in n D, \forall t, \\
I^{G}(t) P_{i, \min }^{G} \leq\left[\widetilde{P}_{i, \text { low }}^{G}(t), \widetilde{P}_{i, u p}^{G}(t)\right] \leq I^{G}(t) P_{i, \max }^{G}, \forall i \in n G, \forall t, \\
-P_{\max }^{L} \leq\left[\widetilde{P}_{\text {low }}^{L}(t), \widetilde{P}_{\text {up }}^{L}(t)\right] \leq P_{\max }^{L}, \forall L, \forall t, \\
\Delta_{\text {DOWN }}^{G}(t) \leq \widetilde{P}_{i, u p}^{G}(t+1)-\widetilde{P}_{i, \text { up }}^{G}(t) \leq \Delta_{\text {UP }}^{G}(t), \forall i \in n G, \forall t, \\
\Delta_{\text {DOWN }}^{G}(t) \leq \widetilde{P}_{i, \text { up }}^{G}(t+1)-\widetilde{P}_{i, \text { low }}^{G}(t) \leq \Delta_{\text {UP }}^{G}(t), \forall i \in n G, \forall t, \\
\Delta_{\text {DOWN }}^{G}(t) \leq \widetilde{P}_{i, \text { low }}^{G}(t+1)-\widetilde{P}_{i, \text { up }}^{G}(t) \leq \Delta_{U P}^{G}(t), \forall i \in n G, \forall t, \\
\Delta_{\text {DOWN }}^{G}(t) \leq \widetilde{P}_{i, \text { low }}^{G}(t+1)-\widetilde{P}_{i, \text { up }}^{G}(t) \leq \Delta_{U P}^{G}(t), \forall i \in n G, \forall t .
\end{gathered}
$$


The affine form required for solving the model can be expressed as

$$
\begin{gathered}
\widetilde{P}_{i, u p}(t)=P_{i, 0}(t)+\sum_{j \in N} P_{i j}(t) \varepsilon_{j, u p}, \forall i \in N, \forall t, \\
\widetilde{P}_{i, \text { low }}(t)=P_{i, 0}(t)+\sum_{j \in L} P_{i j}(t) \varepsilon_{j, l o w}, \forall i \in N, \forall t, \\
\widetilde{P}_{\text {up }}^{L}(t)=B_{i j}\left[\left(\theta_{i, 0}(t)-\theta_{j, 0}(t)\right)+\sum_{k \in N}\left(\theta_{i k}(t)-\theta_{j k}(t)\right) \varepsilon_{k, u p}(t)\right], \forall i, j \in L, \forall t, \\
\widetilde{P}_{\text {low }}^{L}(t)=B_{i j}\left[\left(\theta_{i, 0}(t)-\theta_{j, 0}(t)\right)+\sum_{k \in N}\left(\theta_{i k}(t)-\theta_{j k}(t)\right) \varepsilon_{k, l o w}(t)\right], \forall i, j \in L, \forall t,
\end{gathered}
$$

In the final optimization model, Equation (58) is the objective function. It includes two parts, as shown in Equations (59) and (60), which are the minimum values of the lower and upper limits of the cost interval, respectively. Equations (61) and (62) show that the upper and lower limits of the affine form of the generation bus should be equal to the given total net load, such that the interval equation for power balance is strictly satisfied. Equations (63) and (64) show that the affined load interval is consistent with the given load interval. Equations (65) and (66) show that the generation and line intervals should be within the limit. Equations (67) to (70) show the extended ramping constraints, such that the scenarios represented by the interval can be satisfied as long as the ramping requirements can be satisfied under the boundary conditions.

The cost interval can be accurately and rapidly determined by a deterministic model, which can be conveniently solved using any commercial LP software package. Figure 3 shows the computational flowchart. Note that the objective function includes two parts: the startup/shutdown cost and operating cost. The operating cost is represented as an interval, which can be conveniently determined using the method proposed in this section; the startup/shutdown cost is an integer variable and can be directly determined when the unit commitment is scheduled. The interval for the objective function is determined by combining the two costs.

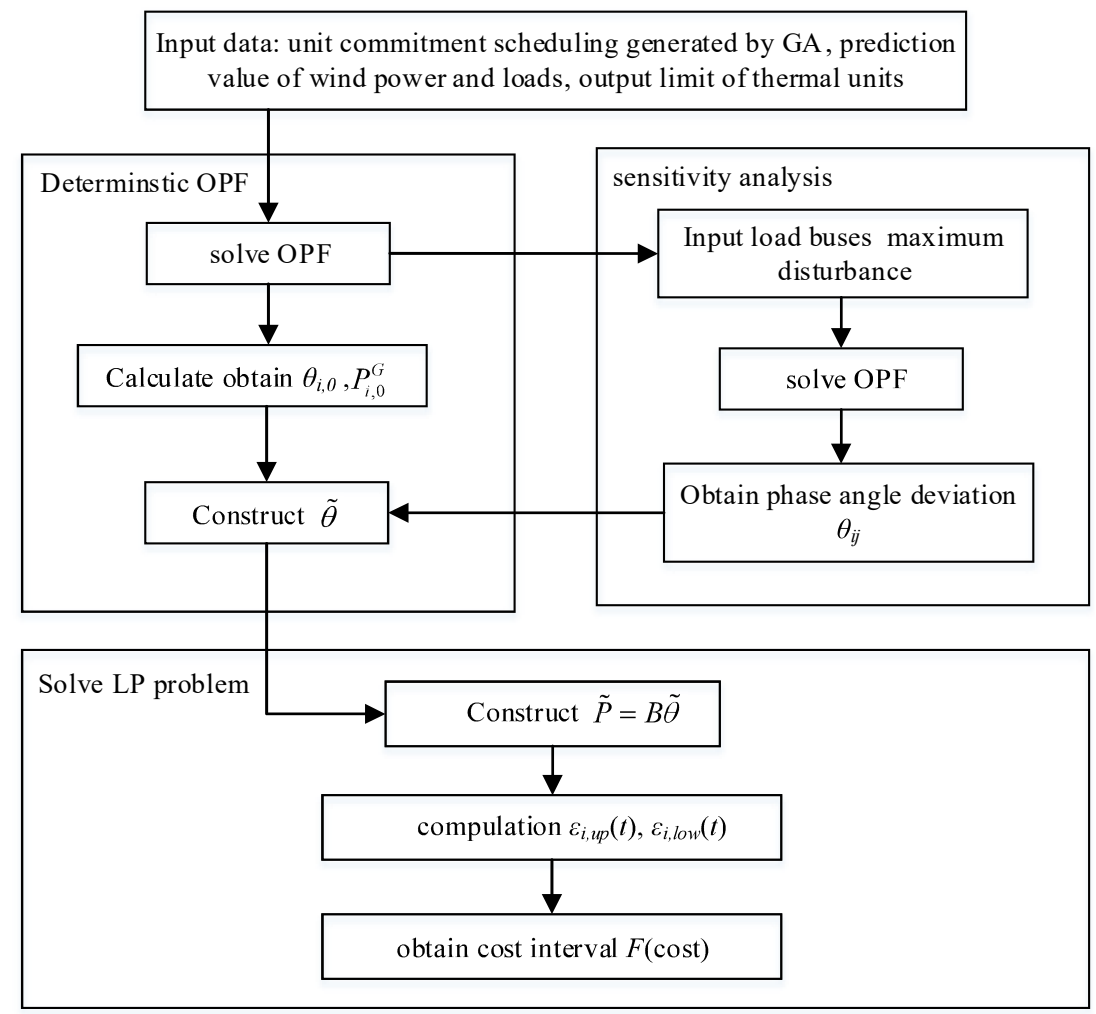

Figure 3. Flowchart for the affine arithmetic-based computation of cost interval. 


\section{Case study}

\subsection{Data}

The case is a modified IEEE-39 bus system, as shown in Figure 4. The system consists of 10 generation units with a total installed capacity of $6512 \mathrm{MW}$ and 17 load buses with a total load of $6147 \mathrm{MW}$. Four wind farms with a total capacity of $800 \mathrm{MW}$ were integrated into the system at bus numbers 28, 30,37, and 38 respectively. Table 1 lists the parameters of the thermal units; the economic data were collected from an actual power grid. The wind power data and load profile data were also collected from an actual power grid. Table 2 lists the load data. The significant wind power penetration results in significant alteration and variation in the power flow. Therefore, the capacities of the following tie-line were increased by $30 \%: 2-3,17-27,25-37$, and 26-27. Table 3 presents the losses of the units at different operating conditions; the data were obtained from Lin et al. [2] and the Steam Turbine Manual $[25,26]$. The costs of coal and diesel (for oil injection) are the prices during the winter of 2017, at 550 and 6130 yuan/ton, respectively.

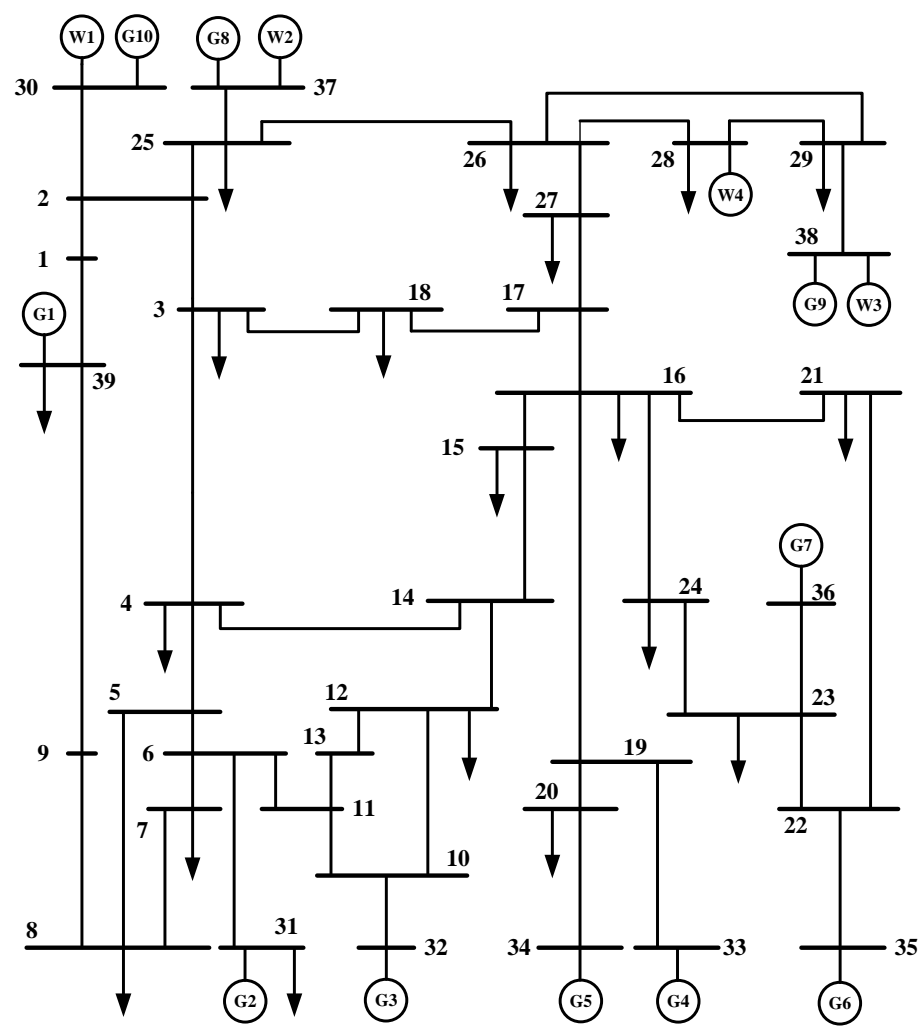

Figure 4. Modified IEEE-39 bus system.

Table 1. Parameters of the thermal units.

\begin{tabular}{|c|c|c|c|c|c|c|c|c|c|c|c|}
\hline \multirow{2}{*}{ Unit } & \multirow{2}{*}{$\begin{array}{l}\text { Maximum } \\
\text { Power } \\
\text { (MW) }\end{array}$} & \multirow{2}{*}{$\begin{array}{c}\operatorname{Ramp} \\
\text { Up } \\
(\mathrm{MW} / \mathrm{h})\end{array}$} & \multirow{2}{*}{$\begin{array}{l}\text { Ramp } \\
\text { Down } \\
\text { (MW/h) }\end{array}$} & \multirow{2}{*}{$\begin{array}{l}\text { Minimum } \\
\text { Up Time } \\
\text { (h) }\end{array}$} & \multirow{2}{*}{$\begin{array}{l}\text { Minimum } \\
\text { Down } \\
\text { Time (h) }\end{array}$} & \multicolumn{3}{|c|}{ Coal Consumption } & \multirow{2}{*}{$\begin{array}{l}\text { Startup/Shutdown } \\
\text { Cost (thousand } \\
\text { RMB) }\end{array}$} & \multirow{2}{*}{$\begin{array}{l}\text { Unit Purchase } \\
\text { Cost (million } \\
\text { RMB) }\end{array}$} & \multirow{2}{*}{$\begin{array}{c}\text { Oil } \\
\text { Injection } \\
(\mathrm{t} / \mathrm{h})\end{array}$} \\
\hline & & & & & & $\mathbf{a}$ & $\mathbf{b}$ & c & & & \\
\hline G1 & 250 & 80 & 80 & 5 & 5 & 0.168 & 265 & 6000 & 280 & 1350 & 2.3 \\
\hline G2 & 576 & 130 & 130 & 9 & 9 & 0.048 & 257 & 18,000 & 600 & 2610 & 4.8 \\
\hline G3 & 650 & 200 & 200 & 9 & 9 & 0.044 & 256 & 18,000 & 600 & 2710 & 4.8 \\
\hline G4 & 632 & 190 & 190 & 9 & 9 & 0.046 & 251 & 18,000 & 600 & 2700 & 4.8 \\
\hline G5 & 508 & 150 & 150 & 9 & 9 & 0.044 & 263 & 18,000 & 600 & 2730 & 4.8 \\
\hline G6 & 650 & 200 & 200 & 9 & 9 & 0.042 & 251 & 18,000 & 600 & 2650 & 4.8 \\
\hline G7 & 560 & 170 & 170 & 9 & 9 & 0.043 & 263 & 18,000 & 600 & 2550 & 4.8 \\
\hline G8 & 540 & 160 & 160 & 9 & 9 & 0.042 & 261 & 18,000 & 600 & 2580 & 4.8 \\
\hline G9 & 830 & 250 & 250 & 10 & 10 & 0.041 & 223 & 24,000 & 700 & 3280 & 5.9 \\
\hline G10 & 1000 & 350 & 350 & 10 & 10 & 0.062 & 185 & 45,000 & 900 & 4760 & 7.0 \\
\hline
\end{tabular}


Table 2. Load data.

\begin{tabular}{cccccccc}
\hline Bus No. & $\begin{array}{c}\text { Active Power } \\
\text { (MW) }\end{array}$ & Bus No. & $\begin{array}{c}\text { Active Power } \\
\text { (MW) }\end{array}$ & Bus No. & $\begin{array}{c}\text { Active Power } \\
\text { (MW) }\end{array}$ & Bus No. & $\begin{array}{c}\text { Active Power } \\
\text { (MW) }\end{array}$ \\
\hline 3 & 322 & 15 & 320 & 23 & 247 & 28 & 206 \\
4 & 500 & 16 & 329 & 24 & 308 & 29 & 283 \\
7 & 233 & 18 & 158 & 25 & 224 & 31 & 9 \\
8 & 522 & 20 & 680 & 26 & 139 & 39 & 1104 \\
12 & 8.5 & 21 & 274 & 27 & 281 & & \\
\hline
\end{tabular}

Table 3. Unit loss data.

\begin{tabular}{cccc}
\hline $\begin{array}{c}\text { Unit Regulation } \\
\text { Degree (\%) }\end{array}$ & $\begin{array}{c}\text { Number of Cycles to } \\
\text { Failure of Rotor }\end{array}$ & $\begin{array}{c}\text { Unit Regulation } \\
\text { Degree (\%) }\end{array}$ & $\begin{array}{c}\text { Number of Cycles to } \\
\text { Failure of Rotor }\end{array}$ \\
\hline 55 & $7.69 \times 10^{4}$ & 70 & $5.26 \times 10^{4}$ \\
60 & $6.25 \times 10^{4}$ & 75 & $4.54 \times 10^{4}$ \\
65 & $5.88 \times 10^{4}$ & 80 & $4.16 \times 10^{4}$ \\
\hline
\end{tabular}

\subsection{Comparative Analysis of Algorithms}

The algorithm proposed in this paper was validated by comparing it with the algorithm proposed by Wang et al. [16]. The algorithm proposed in [16] was intended to obtain the optimal forecast value of the objective function, which is an integer variable. The algorithm proposed in this paper is intended to obtain the optimal interval of the objective function, which is an interval variable. In Algorithm 1, the objective function is the optimal forecast value. In Algorithm 2 (proposed method), the objective function is the optimal interval.

\subsubsection{Results for Different Wind Power Prediction Errors}

Figure 5 compares the optimal cost intervals obtained using Algorithms 1 and 2 at different wind prediction errors. The memberships of the objective function used for Algorithm 2 were $\mu_{f 1}=1$ and $\mu_{f 2}=0.5$.

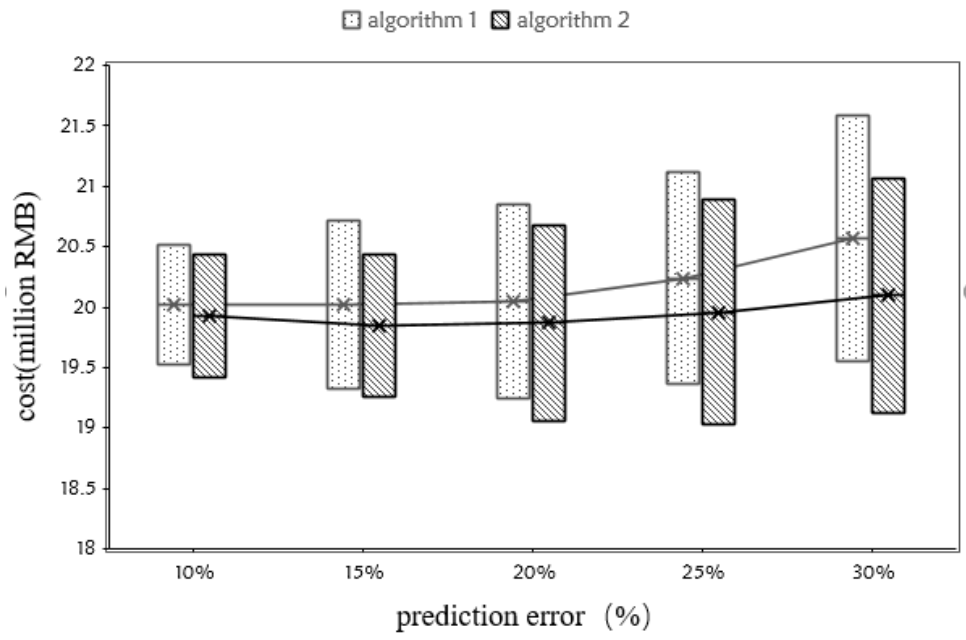

Figure 5. Optimal cost intervals in Algorithm 1 and Algorithm 2.

The upper and lower limits, shown in Figure 5, are the upper and lower limits of the obtained cost intervals. The points connected by the two full lines are the midpoints of the cost intervals at different levels of wind prediction error in Algorithms 1 and 2.

Both the upper and lower limits of the intervals computed using Algorithm 2 are better than those computed using Algorithm 1, particularly at high levels of prediction error. Furthermore, because of the increase in the kilowatt generation cost, the total cost increases with the increase in the level of 
wind power prediction error, particularly when the range of wind power prediction error is $25 \%$ to $30 \%$.

In addition, from the viewpoint of the interval midpoint, the result obtained using Algorithm 2 is better than that obtained using Algorithm 1. At a prediction error of $30 \%$, the difference between the midpoints of the intervals obtained using the two algorithms is 340 thousand yuan. Thus, the effectiveness of Algorithm 2 has been validated.

\subsubsection{Comparative Analysis of the Unit Commitment Schedules Obtained Using Different Algorithms}

Tables 4 and 5 present the unit commitment schedules obtained using the two algorithms, respectively, at a prediction error of 20\%. In Algorithm 1, five units (G1, G3, G4, G7, and G8) with a total capacity of $2632 \mathrm{MW}$ were shut down at nighttime; in Algorithm 2, five units (G1, G3, G4, G8, and G9) with a total capacity of $2902 \mathrm{MW}$ were shut down. The shutdown capacity in the schedules obtained using Algorithm 2 is slightly higher than that in the schedules obtained using Algorithm 1. This implies that, in Algorithm 1, when the active power of the wind farms is high, more units are required for deep peak regulation.

Table 4. Unit commitment schedule obtained using Algorithm 1.

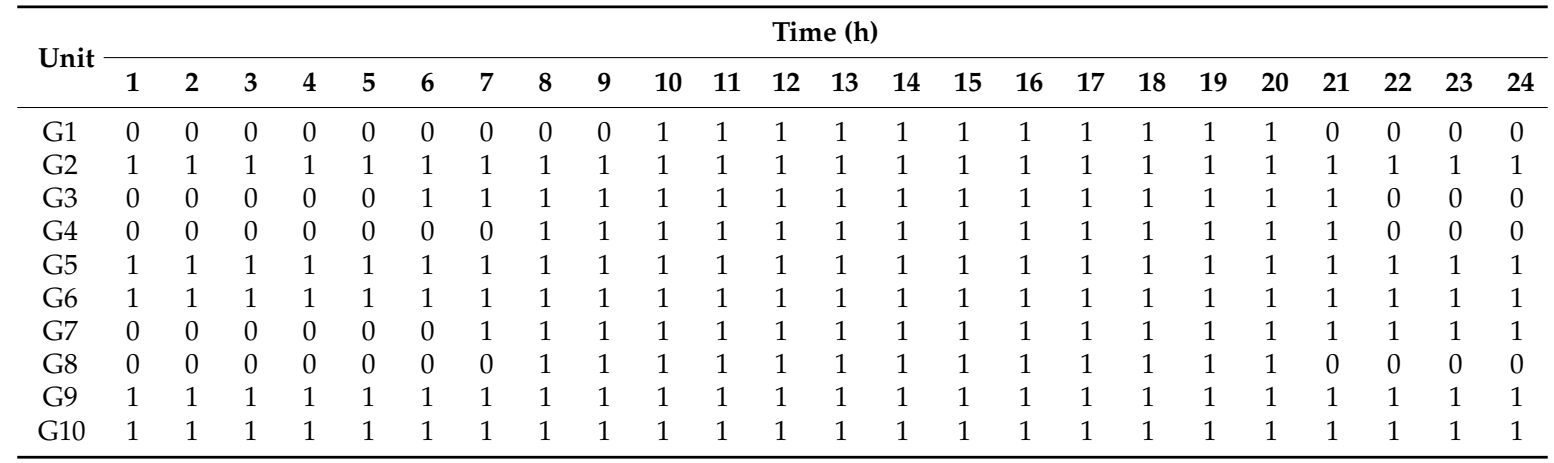

Table 5. Unit commitment schedule obtained using Algorithm 2.

\begin{tabular}{|c|c|c|c|c|c|c|c|c|c|c|c|c|c|c|c|c|c|c|c|c|c|c|c|c|}
\hline \multirow{2}{*}{ Unit } & \multicolumn{24}{|c|}{ Time (h) } \\
\hline & 1 & 2 & 3 & 4 & 5 & 6 & 7 & 8 & 9 & 10 & 11 & 12 & 13 & 14 & 15 & 16 & 17 & 18 & 19 & 20 & 21 & 22 & 23 & 24 \\
\hline G1 & 0 & 0 & 0 & 0 & 1 & 1 & 1 & 1 & 1 & 1 & 0 & 0 & 0 & 0 & 0 & 0 & 0 & 0 & 0 & 0 & 0 & 0 & 0 & 0 \\
\hline G2 & 1 & 1 & 1 & 1 & 1 & 1 & 1 & 1 & 1 & 1 & 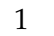 & 1 & 1 & 1 & 1 & 1 & 1 & 1 & 1 & 1 & 1 & 1 & 1 & 1 \\
\hline G3 & 0 & 0 & 0 & 0 & 0 & 1 & 1 & 1 & 1 & 1 & 1 & 1 & 1 & 1 & 1 & 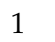 & 1 & 1 & 1 & 1 & 1 & 0 & 0 & 0 \\
\hline G4 & 0 & 0 & 0 & 0 & 0 & 0 & 1 & & 1 & 1 & 1 & & 1 & 1 & 1 & 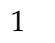 & 1 & 1 & 1 & 1 & 1 & 1 & 1 & 1 \\
\hline G5 & 1 & 1 & 1 & 1 & 1 & 1 & 1 & 1 & & 1 & 1 & & & 1 & 1 & 1 & 1 & 1 & 1 & 1 & 1 & 1 & 1 & 1 \\
\hline G6 & 1 & 1 & 1 & 1 & 1 & 1 & 1 & 1 & 1 & 1 & 1 & 1 & 1 & 1 & 1 & 1 & 1 & 1 & 1 & 1 & L & | & 1 & 1 \\
\hline G7 & 1 & 1 & 1 & 1 & 1 & 1 & 1 & 1 & 1 & 1 & 1 & 1 & 1 & 1 & 1 & 1 & 1 & 1 & 1 & 1 & 1 & 1 & 1 & 1 \\
\hline G8 & 0 & 0 & 0 & 0 & 0 & 0 & 0 & 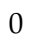 & 1 & 1 & 1 & 1 & 1 & 1 & 1 & 1 & 1 & 1 & 1 & 1 & 0 & 0 & 0 & 0 \\
\hline G9 & 0 & 0 & 0 & 0 & 0 & 0 & 0 & 2 & 1 & 1 & 1 & 1 & 1 & 1 & 1 & 1 & 1 & 1 & 1 & 1 & 0 & 0 & 0 & 0 \\
\hline G10 & 1 & 1 & 1 & 1 & 1 & 1 & 1 & 1 & 1 & 1 & 1 & 1 & 1 & 1 & 1 & 1 & 1 & 1 & 1 & 1 & 1 & 1 & 1 & 1 \\
\hline
\end{tabular}

Figure 6 shows the total capacity of the operating generators obtained using Algorithms 1 and 2. This figure demonstrates that the operating capacity obtained using Algorithm 2 is remarkably lower than that obtained using Algorithm 1 in nighttime. This can be explained by the fact that the kilowatt generation cost increases with the increase in the unit power regulation degree, particularly in the DPRO stage. Using Algorithm 1, the operation cost in the wind power prediction scenario can be reduced by reducing shutdown. However, in the lower-limit wind power scenario, this approach requires more units to operate in the DPRO stage, leading to a dramatic increase in the lower limit of the cost interval and thus an overall higher cost interval. In contrast, the proposed algorithm selects the overall interval as the objection function. Thus, it effectively avoids this operation status and gives a better interval. 


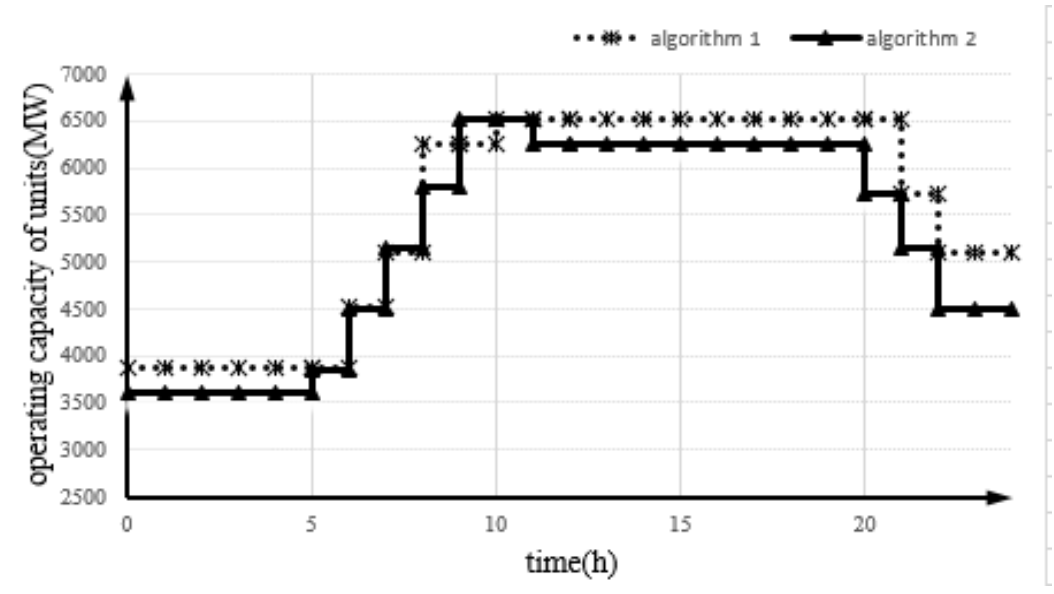

Figure 6. Operating capacity of units obtained using Algorithms 1 and 2.

\subsection{Sensitivity Analysis}

When the thermal units operate in the deep peak regulation stage, the cost of oil injection and the cost of unit loss will significantly affect the operation cost. This section analyzes the characteristics of the optimal operation cost interval under different important parameters.

\subsubsection{Sensitivity Analysis 1: Cost of Unit Loss}

Thermal units operating in deep peak regulation lead to unit loss costs, which are directly related to the unit purchase cost. At present, the per-million-watt unit purchase cost is approximately 4.5-5.3 million yuan.

Figure 7 shows the optimal cost interval under different unit purchase costs. The five sensitivity cases of the per-million-watt unit purchase cost are 3.5 million yuan, 4 million yuan, 4.5 million yuan, 5.0 million yuan, and 5.5 million yuan. It can be observed that with the increase in unit purchase cost, the midpoints of the optimal cost intervals continue to increase, but by only $1.22 \%$, owing to the low proportion of the unit loss cost in the thermal unit operation costs. In addition, with the increase in unit loss cost, the width of the optimal operation interval decreases owing to the large increase in the unit loss cost under the wind overestimation scenario, which increases the lower limit of the operation cost intervals.

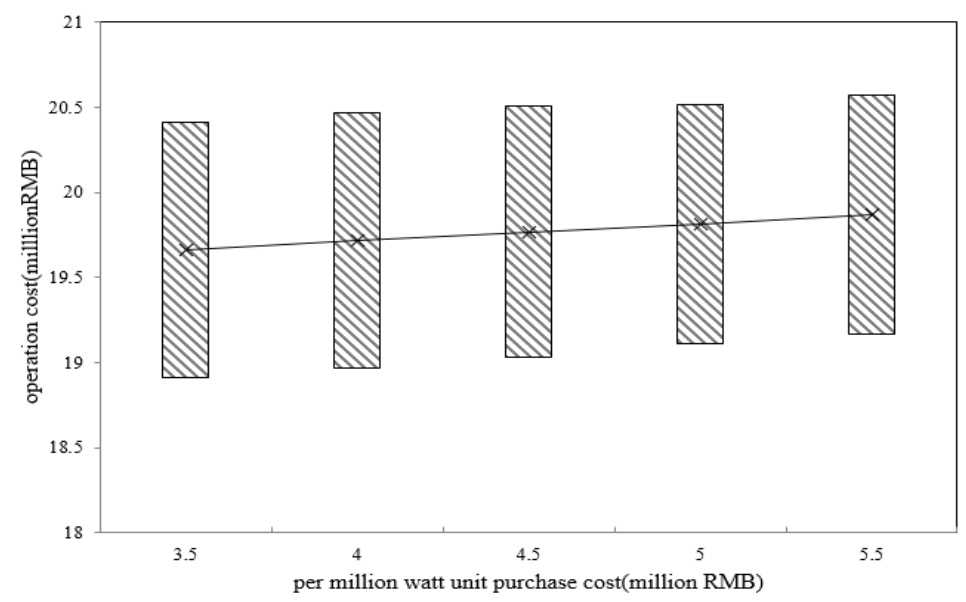

Figure 7. Optimal operation cost interval under different unit purchase costs. 


\subsubsection{Sensitivity Analysis 2: Cost of Oil Injection for Thermal Units}

When the thermal units operate in deep peak regulation with the oil injection stage, an oil injection cost will occur. This part of the cost is relatively high, which will significantly increase the kilowatt generation cost and significantly affect the final operation cost intervals.

Figure 8 shows the optimal cost intervals under different oil injection costs. The five sensitivity cases of oil injection cost are 4500 yuan/ton, 5000 yuan/ton, 5500 yuan/ton, 6000 yuan/ton, and 6500 yuan/ton. It can be observed that with the increase in oil injection cost, the midpoint of the optimal operation cost interval rises sharply, reaching $4 \%$ as the oil injection cost accounts for a relatively high proportion of the operation cost. Once the thermal units operate in deep regulation with the oil injection stage, oil injection is required every hour for each thermal unit to stabilize the combustion of the boiler. In addition, with the increase in oil injection cost, the width of the optimal operation cost interval decreases significantly owing to the increase in oil injection under the wind overestimation scenario, which results in a sharp increase in the lower limits of the operation cost intervals.

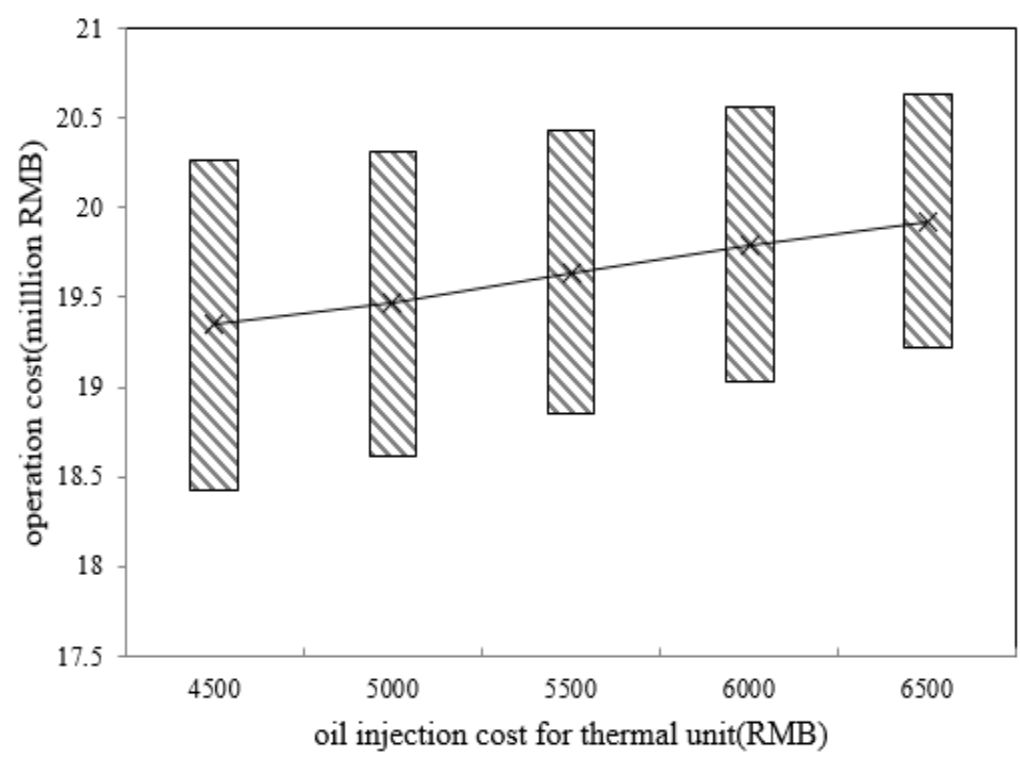

Figure 8. Optimal operation cost interval under different oil injection costs.

\subsection{Analysis of the Thermal Units Operating under Deep Peak Regulation}

This section analyzes wind power integration and various operating costs in the different modes of peak regulation.

The analysis in this section is also based on the IEEE 39-bus system. The same parameters as those used in the previous section are used in this section, except for the wind power prediction error, which is set at $20 \%$ in this section. The wind penetration is the rate of wind power in the prediction scenario.

Case 1: concentrated wind power integration, with wind power connected at four buses: 28,30 , 37 , and 38.

Case 2: distributed wind power integration, with wind power connected at seven buses: 20, 27, $28,29,16,13$, and 23.

Tables 6 and 7 present the results based on the concentrated and distributed wind power integrations, respectively, including the allowable wind penetration and various costs (operating cost, loss cost, oil injection cost of generation units, and kilowatt generation cost) in the different regulation modes. 
Table 6. Computation results based on concentrated integration.

\begin{tabular}{cccccc}
\hline $\begin{array}{c}\text { Degree of Thermal Unit } \\
\text { Regulation }\end{array}$ & $\begin{array}{c}\text { Allowable Wind } \\
\text { Penetration (\%) }\end{array}$ & $\begin{array}{c}\text { Operating Cost of } \\
\text { Generation Units } \\
\text { (million RMB) }\end{array}$ & $\begin{array}{c}\text { Cost of Unit Losses } \\
\text { (million RMB) }\end{array}$ & $\begin{array}{c}\text { Cost of Oil } \\
\text { Injection for Units } \\
\text { (million RMB) }\end{array}$ & $\begin{array}{c}\text { Kilowatt } \\
\text { Generation Cost } \\
\text { (RMB) }\end{array}$ \\
\hline $\begin{array}{c}\text { Regular peak regulation } \\
\begin{array}{c}\text { Deep peak regulation } \\
\text { without oil injection }\end{array}\end{array}$ & 19.7 & {$[19.55,21.05]$} & 0 & 0 & {$[0.146,0.157]$} \\
$\begin{array}{c}\text { Deep peak regulation } \\
\text { with oil injection }\end{array}$ & 25.6 & {$[18.69,20.13]$} & {$[0.41,0.59]$} & 0 & {$[0.143,0.153]$} \\
\hline
\end{tabular}

Table 7. Computation results based on distributed integration of wind power.

\begin{tabular}{cccccc}
\hline $\begin{array}{c}\text { Degree of Thermal Unit } \\
\text { Regulation }\end{array}$ & $\begin{array}{c}\text { Allowable Wind } \\
\text { Penetration (\%) }\end{array}$ & $\begin{array}{c}\text { Operating Cost of } \\
\text { Generation Units } \\
\text { (million RMB) }\end{array}$ & $\begin{array}{c}\text { Cost of Unit Losses } \\
\text { (million RMB) }\end{array}$ & $\begin{array}{c}\text { Cost of Oil } \\
\text { Injection for Units } \\
\text { (million RMB) }\end{array}$ & $\begin{array}{c}\text { Kilowatt } \\
\text { Generation Cost } \\
\text { (RMB) }\end{array}$ \\
\hline $\begin{array}{c}\text { Regular peak regulation } \\
\text { Deep peak regulation } \\
\text { without oil injection }\end{array}$ & 24.2 & {$[18.78,19.93]$} & 0 & 0 & {$[0.140,0.148]$} \\
$\begin{array}{c}\text { Deep peak regulation } \\
\text { with oil injection }\end{array}$ & 29.1 & {$[17.98,19.12]$} & {$[0.58,0.73]$} & 0 & {$[0.139,0.145]$} \\
\hline
\end{tabular}

The table reveals that, in all the three different regulation modes, regular peak regulation can achieve $19.7 \%-24.2 \%$ wind penetration. In contrast, deep peak regulation without oil injection can effective increase wind penetration, with a higher cost of unit loss but lower kilowatt generation cost. In the DPRO stage, the wind penetration rate can be further increased; however, the addition of the oil injection cost and the dramatic increase in the fuel cost result in a noticeable increase in the kilowatt generation cost. More specifically, with the increased rate of cheaper wind power combined, the kilowatt generation cost still increased by $7 \%$.

Compared to the concentrated integration of wind power, the distributed integration of wind power contributes to higher wind penetration and a lower kilowatt generation cost. Despite requiring more units for the peak regulation, this leads to a higher unit loss and oil injection cost. Nevertheless, the distributed integration is more economical than the concentrated distribution.

\section{Conclusions}

In this study, an interval arithmetic-based unit commitment model was proposed for deep peak regulation-oriented unit commitment optimization. In the model, various costs of generation units under the working condition of deep peak regulation were considered, and the interval solution of the objective function was controlled by assessing both the width and midpoint of the desired interval. The method was found to be more effective than a prediction optimization-based method at different wind power prediction accuracies. This is because a deeper level of thermal unit regulation results in a dramatic increase in the unit power cost, particularly in the DPRO stage. Prediction optimization-based algorithms improve the economic performance of the system in different prediction scenarios by minimizing shutdown. However, under the condition of significant wind power penetration, this approach requires more generation units to operate in the DPRO stage, thus significantly increasing the lower limit of the cost interval. In contrast, the interval optimization method proposed in this paper effectively avoids this scenario, thereby obtaining more optimal cost intervals.

The effects of different levels of peak regulation on the unit commitment solution were also analyzed. The wind penetration rates and power costs at different levels of generation of unit power regulation in two different wind power integration scenarios, such as the concentrated and distributed integrations, were computed. The results demonstrate that, compared to regular peak regulation, deep peak regulation without oil injection contributed to significantly higher wind penetration rates as well as lower power generation costs. Deep peak regulation with oil injection results in a dramatic increase in unit power cost but an insignificant increase in wind power penetration. Compared to concentrated wind power integration, distributed wind power integration results in more severe 
generation unit loss and higher oil injection costs but leads to better economic performance and allows higher wind penetration.

Author Contributions: Y.Y., C.Q., Y.Z. and C.W. conceived and designed the study; Y.Y. analyzed the data and wrote the paper; C.Q. and Y.Z. helped analyze the data and edited the figures and tables; Y.Y., C.Q., Y.Z. and C.W. checked the results of this work. All the authors have contributed significantly.

Funding: This work was supported by the National Nature Science Foundation of China $(51507108,51337005)$.

Conflicts of Interest: The authors declare no conflict of interest.

\section{Nomenclature}

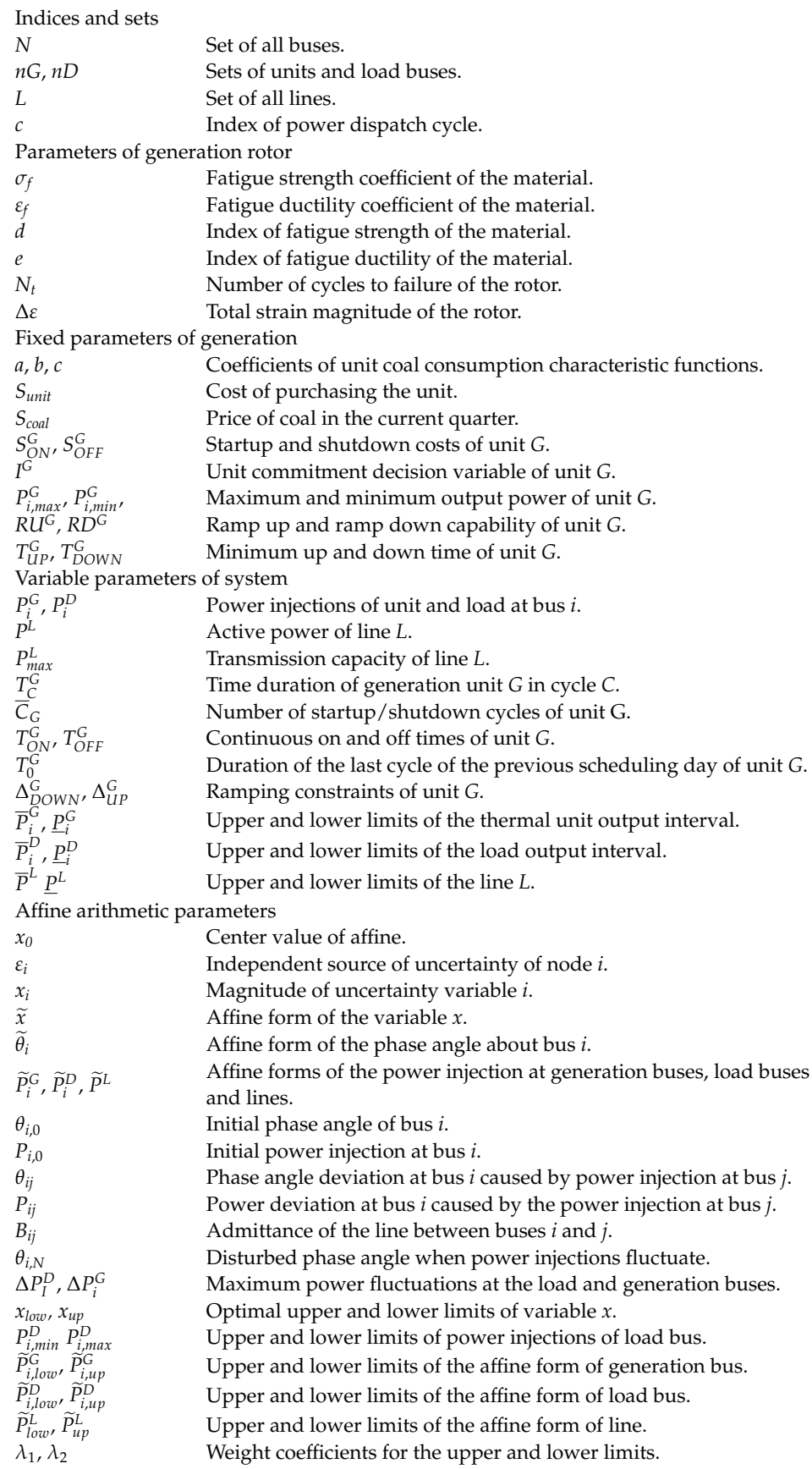




\section{References}

1. Xiang, T.; Chen, H.; Jiang, X. Assessing the effect of wind power peaking characteristics on the maximum penetration level of wind power. IET Gener. Transm. Distrib. 2015, 9, 2466-2473.

2. Lin, L.; Zou, L.; Zhou, P.; Tian, X.Y. Multi-angle economic analysis on deep peak regulation of thermal power units with large-scale wind power integration. Autom. Electr. Power Syst. 2017, 41, 21-27.

3. Lin, L.; Zou, L.; Tian, X.Y. Analysis of deep peak regulation and its benefit of thermal units in power system with large scale wind power integrated. Power Syst. Technol. 2017, 41, 2255-2263.

4. Lin, L.; Tian, X.Y.; Cai, X.X. Gas unit deep peak regulation and power system energy efficiency in consideration of conditional cost. Autom. Electr. Power Syst. 2017, 42, 16-23.

5. Xie, T.; Lv, K.; Huang, J.S. Study on the thermodynamic characteristic of generalized regenerative system used for deep peak load regulating operation. Therm. Power Gener. 2018, 5, 71-76.

6. Cheng, D.V. Peak-Adjusting Flexibility Research of Combined Steam Turbine Based on Double Rotor Double Back Pressure Heating Reconstruction Technology during Heat Period. Master's Thesis, Shandong University, Shandong, China, 2017.

7. Wan, C.; Wang, J.; Lin, J. Nonparametric Prediction Intervals of Wind Power via Linear Programming. IEEE Trans. Power Syst. 2018, 33, 1074-1076. [CrossRef]

8. Elattar, E.E. Prediction of wind power based on evolutionary optimised local general regression neural network. IET Gener. Transm. Distrib. 2014, 8, 916-923. [CrossRef]

9. Qian, Z.; Pei, Y.; Cao, L.; Wang, J.; Jing, B. Review of wind power forecasting method. High Volt. Eng. 2016, 42, 1047-1060.

10. Wang, C.; Liu, F.; Wang, J. Robust Risk-Constrained Unit Commitment with Large-scale Wind Generation: An Adjustable Uncertainty Set Approach. IEEE Trans. Power Syst. 2016, 32, 723-733. [CrossRef]

11. Canan, U.; Botterud, A.; Birge, J.R. An Improved Stochastic Unit Commitment Formulation to Accommodate Wind Uncertainty. IEEE Trans. Power Syst. 2016, 31, 2507-2517.

12. Shao, C.; Wang, X.; Shahidehpour, M. Security-Constrained Unit Commitment with Flexible Uncertainty Set for Variable Wind Power. IEEE Trans. Sustain. Energy 2017, 8, 1237-1246. [CrossRef]

13. Hargreaves, J.J.; Hobbs, B.F. Commitment and dispatch with uncertain wind generation by dynamic programming. IEEE Trans. Sustain. Energy 2012, 3, 724-734. [CrossRef]

14. Xu, C.; Gu, W.; Gao, F.; Song, X.; Meng, X.; Fan, M. Improved affine arithmetic based optimization model for interval power flow analysis. IET Gener. Transm. Distrib. 2016, 10, 3910-3918. [CrossRef]

15. Saric, A.T.; Stankovic, A.M. An application of interval analysis and optimization to electric energy markets. IEEE Trans. Power Syst. 2006, 21, 515-523. [CrossRef]

16. Zhang, C.; Chen, H.; Ngan, H.; Liang, Z.; Guo, M.; Hua, D. Solution of reactive power optimization including interval uncertainty using genetic algorithm. IET Gener. Transm. Distrib. 2017, 11, 3657-3664. [CrossRef]

17. Huang, C.; Yue, D.; Xie, J.; Li, Y.; Wang, K. Economic dispatch of power systems with virtual power plant based interval optimization method. CSEE J. Power Energy Syst. 2016, 2, 74-80. [CrossRef]

18. Wang, Y.; Xia, Q.; Kang, C. Unit commitment with volatile node injections by using interval optimization. IEEE Trans. Power Syst. 2011, 26, 1705-1713. [CrossRef]

19. Vaccaro, A. Affine Arithmetic for Power and Optimal Power Flow Analyses in the Presence of Uncertainties. Ph.D. Thesis, University of Waterloo, Waterloo, ON, Canada, 2015.

20. Wang, S.; Han, L.; Zhang, P. Affine arithmetic-based DC power flow for automatic contingency selection with consideration of load and generation uncertainties. Electr. Power Compon. Syst. 2014, 42, 852-860. [CrossRef]

21. Vaccaro, A.; Cañizares, C.A. An affine arithmetic-based framework for uncertain power flow and optimal power flow studies. IEEE Trans. Power Syst. 2017, 32, 274-288. [CrossRef]

22. Pirnia, M.; Cañizares, C.A.; Bhattacharya, K.; Vaccaro, A. A novel affine arithmetic method to solve optimal power flow problems with uncertainties. IEEE Trans. Power Syst. 2014, 29, 2775-2783. [CrossRef]

23. Munoz, J.; Canizares, C.; Bhattacharya, K. An Affine Arithmetic-Based Method for Voltage Stability Assessment of Power Systems with Intermittent Generation Sources. IEEE Trans. Power Syst. 2013, 28, 4475-4487. [CrossRef]

24. Damousis, I.G.; Bakirtzis, A.G.; Dokopoulos, P.S. A solution to the unit-commitment problem using integer-coded genetic algorithm. IEEE Trans. Power Syst. 2004, 19, 1165-1172. [CrossRef] 
25. Anderson, P.M.; Agrawal, B.L.; Van Ness, J.E. Sub Synchronous Resonance in Power Systems; Wiley-IEEE Press: New York, NY, USA, 1999; pp. 35-68.

26. Zhang, B.H. Thermal stress and life expenditure of stream turbine rotor for cycling service. Proc. CSEE 1986, 2, 3-15.

(c)

(C) 2019 by the authors. Licensee MDPI, Basel, Switzerland. This article is an open access article distributed under the terms and conditions of the Creative Commons Attribution (CC BY) license (http:/ / creativecommons.org/licenses/by/4.0/). 